Colonial Habits 



\title{
Colonial Habits
}

Convents and the Spiritual Economy of Cuzco, Peru

\author{
K A T H R Y B U R N S
}

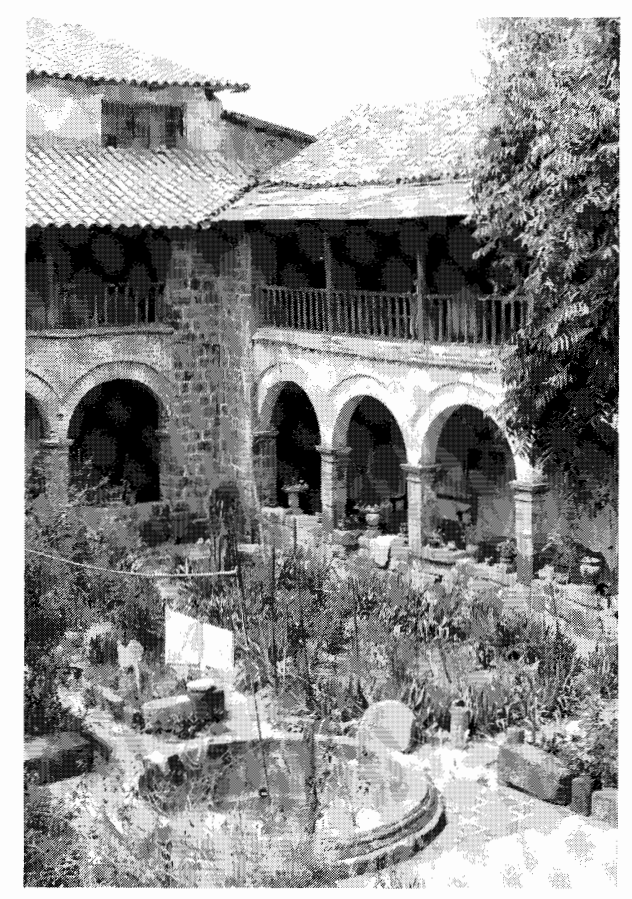

D U K E U I V ER S T Y PRES S

Durham and London, 1999 


\section{(C) 1999 Duke University Press}

All rights reserved. Printed

in the United States of America on

acid-free paper $\infty$ Typeset in Joanna by

Tseng Information Systems, Inc.

Frontispiece: The first cloister of Santa

Catalina de Sena in Cuzco. Photo by K. Burns.

Library of Congress Cataloging-in-

Publication Data appear on the last

printed page of this book. 
To my family,

especially Roland 
